\title{
Biopolymers
}

\section{for Tissue Engineering}

\author{
Elena D. Nikolaeva* \\ Siberian Federal University \\ 79 Svobodny, Krasnoyarsk, 660041, Russia \\ Institute of Biophysics SB RAS \\ 50/50 Akademgorodok, Krasnoyarsk, 660036, Russia
}

Received 22.04.2014, received in revised form 10.05.2014, accepted 12.06.2014

A brief overview of the biopolymers used for cell and tissue engineering is presented. The results of research of matrices made from resorbable polyhydroxyalkanoates with different composition in fibroblast cell line culture are shown.

Keywords: biopolymers, biocompatibility, biodegradability, polyhydroxyalkanoates, PHAs.

\section{Биополимеры для клеточной}

\section{и тканевой инженерии}

Е.Д. Николаева

Сибирский федеральный университет

Россия, 660041, Красноярск, пр. Свободныий, 79

Институт биофизики СО РАН

Россия, 660036, Красноярск, Академгородок, 50/50

Представлен обзор литературы по применению биополимеров в клеточной и тканевой инженерии. Показаны результаты исследований свойств матриксов, полученных из резорбируемых полимеров полигидроксиалканоатов различного состава, в культуре фибробластов.

Ключевые слова: биополимеры, биосовместимость, биодеградаџия, полигидроксиалканоаты, ПГА.

(C) Siberian Federal University. All rights reserved

* Corresponding author E-mail address: nikolaeva-lena@mail.ru 


\section{Введение}

В настоящее время мировые потребности в донорских органах удовлетворены всего лишь на 10 \%. Для развитых стран, таких как США и страны Западной Европы, этот показатель достигает $15 \%$, однако в России потребности в трансплантации удовлетворены всего на $0,1 \%$, в том числе из-за этико-правовых проблем законодательства (Краснопольская, 2011; Визгунова, 2008; Готье и др., 2009). К главным проблемам трансплантологии относятся острая нехватка донорских органов и сопутствующие операциям осложнения в виде иммунной реакции организма реципиента, отторжений трансплантированных органов, приема дорогостоящих препаратовиммунодепрессантов, опасности переноса инфекций. Поэтому широкие перспективы имеют клеточная и тканевая инженерии, направленные на создание биоискусственных конструкций, предназначенных для замещения поврежденных или утраченных тканей и органов.

В последние годы в связи с активным развитием клеточной и тканевой инженерии активно развивается область материаловедения, связанная с разработкой и получением биополимеров, пригодных для создания подложек и каркасов (другое название - матрикcы, scaffold), на которых клетки способны организовываться в тканеподобные структуры для дальнейшей имплантации в места поврежденных тканей и органов у пациентов.

\section{Требования, предъявляемые к материалам для клеточной и тканевой инженерии}

Использование матриксов связано с тем, что для успешного исхода лечения клеткам необходим субстрат, на котором они могут закрепиться - либо в виде суспензии клеток в гелях, либо в виде моно- или многослоя на каркасах. Матриксы должны обеспечивать поступление питательных веществ к клеткам и удаление продуктов жизнедеятельности, обладать нужными физико-механическими свойствами для поддержки целостности клеток и тканей в течение всего периода имплантации.

Основные требования, предъявляемые к материалам, пригодным для создания матриксов, - это биосовместимость и биоразрушаемость.

Биосовместимость - это способность материала находиться внутри организма без воспалительных и аллергических реакций. В настоящее время нет абсолютно биосовместимых материалов, кроме того, для разных клинических задач необходима разная степень биосовместимости. Например, для имплантатов глаза необходима абсолютная биоинертность материала, в сердечно-сосудистой хирургии используются гемосовместимые материалы, для регенерации костной ткани необходим биоактивный материал, способный индуцировать остеогенез.

На биосовместимость материала влияет не только состав, но и форма имплантата. Матриксы для клеток могут быть в форме гелей, микро- и наносфер, волокон, пленок, различных трехмерных конструкций. Ультратонкие волокна - один из наиболее перспективных типов матриксов, поскольку такая структура в максимальной степени копирует структуру межклеточного матрикса (Kim et al., 2009). К преимуществам гелевых форм матриксов относится большая гидратированность материалов, которая позволяет питательным веществам, газам и отходам жизнедеятельности диффундировать по всему объему матрикса, хорошая биосовместимость, меньшая травматичность при внесении гелей в место имплантации (возможность инъекций); гелевые матриксы полимеризуются in situ под 
действием различных факторов, заполняя тканевые повреждения сложной формы. Однако к недостаткам гелей относятся их слабые механические свойства, несопоставимые с живыми тканями, поэтому в этой области перспективно использование композитов гелей с более прочными материалами (Lin et al., 2009). Для создания гидрогелей могут быть использованы и синтетические, и природные полимеры, структура и свойства которых зависят от состава полимера, типа и количества химических и физических связей поперечных сшивок между полимерными цепями (Drury, Mooney, 2003). Гелевые формы обычно применяют для восстановления мягких тканей, систем доставки лекарств и биоактивных веществ, трансплантации клеток. Особенно перспективно использование гелей для восстановления периферической нервной системы. Микро- и наносферы, изготовленные из синтетических или натуральных биополимеров, чаще всего нужны в качестве систем доставки препаратов и биологически активных веществ, но также могут быть использованы в качестве матриксов для доставки клеток в требуемое место. При этом если материал плохо совместим с живыми тканями, то воспалительная реакция на микросферы значительно возрастает по сравнению с компактными формами за счет увеличения площади соприкосновения материала и тканей организма. Например, политетрафлуороэтилен (тефлон), который достаточно инертен в виде прессованного компакта, в виде порошка вызывает острую реакцию тканей. Хирургические шовные волокна в виде мононитей более биосовместимы по сравнению с многонитчатыми волокнами, изготовленными из того же материала (Park, Lakes, 2007).

Постоянное нахождение имплантата в организме связано с нежелательными побочными действиями: окисление поверхности, воспалительные реакции, экранирование механической нагрузки, необходимой для нормального развития тканей, и необходимость повторной операции для удаления имплантата. Поэтому большое внимание уделяется разработке биоразрушаемых материалов, т.е. способных постепенно разлагаться в организме, желательно со скоростью, сопоставимой со скоростью роста новых тканей и образованием нетоксических продуктов, которые вовлекаются в метаболизм или легко выводятся из организма. Деградация материалов в организме осуществляется гидролитически или ферментативно, поверхностно или во всем объеме матрикса.

Важным параметром при выборе материала для матрикса являются свойства поверхности: гидрофильно-гидрофобный баланс поверхности, шероховатость, заряд.

Было установлено, что для адгезии и пролиферации клеток более благоприятна поверхность со средней гидрофобностью (Jansen et al., 2005). Более гидрофильная поверхность лучше подходит для адгезии белков, таких как фибронектин или коллаген, связывающих клетки с субстратом, а в случае трехмерных пористых матриксов увеличивает проникновение раствора питательных веществ и удаление продуктов жизнедеятельности по сравнению с более гидрофобными материалами. Для повышения гидрофильности поверхности материала используются различные приемы - обработка $\gamma$-облучением, плазмой кислорода, водорода, азота (Tezcaner et al., 2003; Pompe et al., 2007; Lucchesi et al., 2008), обработка щелочью (Pompe et al., 2007), липазой (Yang et al., 2002), покрытие материала стерином, акриламидом, метилметакрилатом и другими веществами в зависимости от требуемого результата. Так, покрытие акриловой кислотой увеличивает гидрофильность поверхности, карбоновые 
кислоты используются для иммобилизации биомолекул, хитозан увеличивает антибактериальную активность (Grøndahl et al., 2005, Hu et al., 2003). Поверхность полимеров можно модифицировать биоактивными молекулами - ростовыми факторами, белками межклеточного матрикса или короткими аминокислотными последовательностями, среди которых наиболее часто используется последовательность аргинин-глицинаспарагиновая кислота (RGD), сигнальный домен фибронектина и ламинина. Подобные модификации проводили на стекле, кварце, оксидах металлов, полимерах (Shin et. al., 2003, Wang et al., 2011). Покрытие биоматериалов RGD-последовательностью или фибриногеном значительно увеличивает адгезию клеток на поверхности и снижает клеточный апоптоз (Brodbeck et al., 2003).

Шероховатость поверхности - другой очень важный параметр, влияющий на гидрофильность поверхности, адсорбцию белков, прикрепляемость клеток и их дальнейший рост, а также на протекание воспалительной реакции. Для разных типов клеток подходят поверхности с различными коэффициентами шероховатости. Например, для остеобластов лучше подходит более шероховатая поверхность с однонаправленной структурой рисунка поверхности (Van den Dolder et al., 2003). Адгезия, пролиферация и дифференцировка клеток костного мозга повышаются с увеличением шероховатости поверхности матрикса (Ji et al., 2009), а для эпителиальных клеток подходит более гладкая поверхность.

Заряд поверхности материалов влияет на адгезию клеток, взаимодействуя с зарядом клеточных мембран и таким образом усиливая взаимодействие между клеткой и субстратом. При использовании материалов для контакта с кровью необходимо, чтобы молекулы материала были отрицательно заряжены, как интима кровеносных сосудов и клетки крови, для предотвращения тромбообразования (Baier, 1972). Заряд поверхности материала также определяет интенсивность воспалительной реакции (Sabokbar et al., 2003)

\section{Типы биополимеров, используемых в клеточной \\ и тканевой инженерии}

В настоящее время известно огромное количество материалов для биомедицины, в том числе биополимеров, которые можно классифицировать по происхождению и химической структуре:

1) природные биополимеры, к ним относятся три класса полимеров: полисахариды и их производные (альгинаты, целлюлоза, карбоксиметил-целлюлоза, хитозан, декстран, гепарин, гиалуроновая кислота, хондроитинсульфат и др.); белки (коллаген, эластин, фибрин, фибронектин, шелк и др.); полигидроксиаканоаты (производные гидроксикислот, синтезируемые прокариотическими организмами в качестве запасного энергетического вещества);

2) синтетические биополимеры, к ним относятся полиэтилен, полиметилметакрилат, полиэтилентерифталат, полиамиды, полиуретаны, силиконы и др.

На основе известных биополимеров создаются тканеинженерные конструкции практически всех систем организма:

- кровеносная - клапаны сердца, элементы сосудов (полиуретаны, полисульфоны, фторуглероды, полиэфиры, коллаген);

- выделительная система - элементы мочеточников, мочевой пузырь (полилактид, полигликолид, полиуретаны, коллаген); 
- нервная система - периферические нервы (фибриновые гели, поли(лактидсо-гликолид), альгинат, хитозан, коллаген, поликапролактон);

- опорно-двигательная - костнозамещающий материал, эндопротезы, восстановление хрящевых тканей (биокерамика, биостекло, сплавы металлов, полилактид, силиконы, глюкозаминогликан, полиметилметакрилат, полифосфорэфиры);

- покровная - эквиваленты кожи на основе полиуретанов, коллагена, фибрина, силиконов, гиалуроновой кислоты.

Несмотря на это, до сих пор не созданы универсальные материалы, соответствующие всем требованиям. Так, природные биополимеры обладают хорошей биосовместимостью, но недостаточной механической прочностью; свойства одного и того же материала (скорость биорезорбции, чистота биополимера) могут достаточно заметно варьировать в зависимости от источника получения материала и способов обработки. Синтетические биополимеры обладают широким спектром механических свойств - от гидрогелей до жестких материалов, их свойства хорошо воспроизводимы, однако биосовместимость неудовлетворительна.

\section{Полигидроксиалканоаты в биомедицине}

Особое место среди биополимеров занимают полигидроксиалканоаты (ПГА) - линейные полиэфиры бактериального происхождения. По ряду физико-химических свойств ПГА сходны с такими синтетическими полимерами, как полиэтилен и полипропилен. ПГА подвержены биологической деградации за счет эндо- и экзодеполимераз до олиго- и мономеров. ПГА обладают хорошей биосов- местимостью, так как один из основных компонентов ПГА 3-гидроксимасляная кислота является промежуточным компонентом цикла трикарбоновых кислот (Reusch et al., 1992).

Благодаря линейной структуре ПГА при нагревании становятся пластичными, показана возможность переработки ПГА общепринятыми способами (экструзия, прессование, электростатическое формование, получение микрочастиц из эмульсий и т.д.) в различные изделия (Williams et al., 1999; Williams, Martin, 2001; Volova et al., 2003; Shishatskaya et al., 2004a; 2006; 2008). Все это делает ПГА перспективными для использования во многих областях медицины - для изготовления шовных и перевязочных материалов, систем депонирования и доставки лекарств, эндопротезов для ортопедии, челюстно-лицевой, сердечно-сосудистой хирургии и т.д. (Волова с соавт., 2006; Zinn et al., 2001).

Известно около 150 различных мономеров, которые могут входить в состав ПГА, синтезируемых разными группами микроорганизмов, в том числе и генетически модифицированных (Steinbüchel, Valentin, 1995). На состав ПГА влияют особенности микроорганизма-продуцента, пути его метаболизма, источники углерода. В зависимости от мономерного состава кристалличность, пластичность, термические свойства ПГА сильно варьируют.

Наиболее изученный представитель ПГА - гомополимер 3-гидроксимасляной кислоты (поли-3-гидроксибутират, ПЗГБ). Очищенные образцы ПЗГБ обладают высокой степенью биосовместимости (Shishatskaya et al., 2004b). К недостаткам ПЗГБ можно отнести жесткость и хрупкость, связанные с большой кристалличностью (70 \%) полимера, медленную скорость деградации in vivo.

Более перспективны сополимерные ПГА, свойства которых в зависимости от соста- 
ва и распределения мономеров варьируют в широких пределах. Несмотря на большое разнообразие ПГА, наиболее перспективными считаются сополимеры, содержащие 3-гидроксивалерат, 4-гидроксибутират, 3-гидроксигексаноат, 3-гидроксиоктаноат. Физико-химические свойства данных сополимеров изучены достаточно хорошо, однако противоречивые результаты исследования биологической совместимости ПГА разного химического состава оставляют открытым вопрос, какому из типов ПГА можно отдать предпочтение.

Сополимер 3-гидроксибутирата с 3-гидроксивалератом (ПЗГБ/3ГВ) - второй по изученности представитель ПГА после ПЗГБ. В зависимости от содержания 3ГВ кристалличность сополимеров варьирует в пределах 39-69 \%. Механические свойства сополимеров, содержащих 3ГВ, в зависимости от соотношения мономеров могут существенно меняться: с увеличением доли 3ГВ полимер становится менее кристаллическим и более эластичным. Температура плавления сополимера ниже по сравнению с ПЗГБ, и чем выше доля 3-гидроксивалерата, тем больше это снижение. Физико-механические свойства также существенно меняются от соотношения мономерных фракций. Проведен ряд работ по исследованию биосовместимости ПЗГБ/3ГВ in vivo (Köse et al., 2003a, 2003b, 2005; Volova et al., 2003; Shishatskaya et al., 2004b), в которых показано, что высокоочищенный сополимер ПЗГБ/ЗГВ вызывал минимальную тканевую реакцию при имплантации животным.

Больший интерес представляют сополимеры, содержащие 4-гидроксибутират и 3-гидроксигексаноат. Сополимеры, содержащие 4-гидроксибутират (ПЗГБ/4ГБ), обладают большей эластичностью, чем гомополимер ПЗГБ, удлинение при разрыве составляет до
1000 \% (у ПЗГБ - до 10 \%). Полимеры с долей 4ГБ 20-40 \% - высокоэластичные резиноподобные полимеры. При увеличении доли 4ГБ от 0 до $49 \%$ кристалличность снижается от 60 до $14 \%$ (Saito and Doi, 1994). Четкой зависимости между соотношением мономеров ЗГБ и 4ГБ и молекулярным весом не выявлено, но наблюдается влияние фракции 4ГБ на температурные свойства - при увеличении содержания 4ГБ в сополимере температура плавления снижается от $175{ }^{\circ} \mathrm{C}$ у гомополимера ПЗГБ до $53{ }^{\circ} \mathrm{C}$ у гомополимера П4ГБ (Hazer, Steinbüchel, 2007). 4-гидроксибутират в виде мономеров присутствует в организмах млекопитающих, поэтому продукты деградации П4ГБ вызывают незначительную воспалительную реакцию.

Благодаря эластичным и биосовместимым свойствам на основе П4ГБ компанией «Терһа» разработан зарегистрированный и одобренный FDA продукт Терhа FLEX®, используемый для создания коммерческих продуктов - хирургических нитей, сеток и пленок. В этой же компании разрабатываются медицинские изделия из материала Терhа ELAST ® - еще более эластичного сополимеpa ПГА (Martin, Williams, 2003).

Сополимеры 3-гидроксибутирата с 3-гидроксигексаноатом (ПЗГБ/ЗГГ) менее кристалличны по сравнению с гомополимером ПЗГБ: с увеличением доли гидроксигексаноата от 0 до 25 мол. \% кристалличность снижается от 60 до 18 \%. Температура плавления полимерных пленок, полученных из растворов ПЗГБ/ЗГГ, снижается от 177 до $52{ }^{\circ} \mathrm{C}$ при увеличении фракции 3-гидроксигексаноата от 0 до 25 мол. \%, механическая прочность с увеличением включения 3ГГ уменьшалась, а удлинение при разрыве возрастало до 85 \% (Doi et al., 1995).

Трехкомпонентные полигидроксиалканоаты содержат 3-гидроксибутират и в качестве 
дополнительных мономеров 3-гидроксивалерат, 3-гидроксигексаноат, 4-гидроксибутират. Плотность, температурные и механические характеристики, молекулярный вес трехкомпонентных сополимеров существенно зависят от соотношения мономеров. Большинство трехкомпонентных сополимеров характеризуется пониженной по сравнению с ПЗГБ температурой плавления и более длительным периодом кристаллизации. В настоящее время имеется небольшое количество работ, посвященных биосовместимости 3-компонентных ПГА (Liu, Chen, 2008; Ji et al., 2008; Ji et al., 2009).

При анализе опубликованных работ по оценке биосовместимости ПГА разного химического состава были выявлены весьма противоречивые результаты. Так, в работе (Wang et al., 2004) показано, что первичная культура остеобластов в тесте МТТ дала лучшие результаты на сополимере 3-гидроксибутирата с 3-гидросигексаноатом, а на ПЗГБ и полилактиде жизнеспособность клеток была ниже на 40 и 60 \% соответственно. При исследовании потенциальной цитотоксичности пленок и нетканого полотна из ПзГБ и ПЗГБ/3ГВ (5 мол. \%) в культурах человеческих остеобластов SaOS-2 и фибробластов мыши L 929 цитотоксичности со стороны всех типов полимеров не зафиксировано и влияния состава полимера на количество клеток не выявлено (Sombatmankhong et al., 2007). В другой работе (Wang et al., 2005) в ходе сравнительного исследования полилактида, ПЗГБ, ПЗГБ/ЗГГ (5, 12 и 20 мол. \%) обнаружено позитивное влияние гидроксигексаноата на жизнеспособность остеобластов только на самом гидрофобном матриксе из сополимера ПЗГБ/ЗГГ с 12 мол. \% фракции

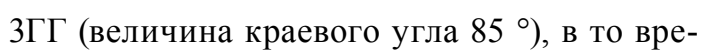
мя как при 5 и 20 мол. \% этого мономера в сополимере результаты были сопоставимы с полученными на матриксах из ПЗГБ и полилактида; при этом в культуре фибробластов линии L 929, напротив, самые высокие показатели получены на пленках из ПЗГБ/ЗГГ при 20 мол. \% 3ГГ. В работе (Ji et al., 2009) при культивировании клеток костного мозга на пленках из ПГА пролиферативная активность клеток на 3-й день культивирования была выше на $30 \%$ на трехкомпонентном полимере (ПЗГБ/ЗГВ/3ГГ) по сравнению с ПЗГБ/ЗГГ, при этом результаты, полученные на ПЗГБ/ЗГГ и на полилактиде, были сходными. При сравнении поверхностей пленок с различной степенью шероховатости и гидрофильности, изготовленных из полилактида, ПЗГБ, сополимеров ЗГБ с ЗГГ (12 мол. \%) и с 4 ББ (7, 12, 20 и 40 мол. \%), в культуре гладкомышечных клеток сосудов кролика RaSMCs авторы не выявили различий в количестве клеток в МТТ-тесте через 24 ч после засева (Cheng et al., 2008); и только через 4 сут обнаружено минимальное количество клеток на ПЗГБ, максимальное - на ПЗГБ/4ГБ (7 мол. \%). Однако при увеличении содержания мономера 4ГБ количество клеток снижалось, приближаясь к показателям на других типах пленок. В другой работе (Chee et al., 2008) при сравнении биосовместимости полилактидгликолида с ПЗГБ и ПЗГБ/4ГБ $(11,22,30$ и 45 мол. \%) в культуре фибробластов линии L 929 оказалось, что через 4 сут в МТT-тесте количество жизнеспособных клеток на сополимере ПЗГБ/4ГБ (45 мол. \%) было в 4 раза выше, чем на ПЗГБ, но при этом сопоставимо с контрольным полилактид-гликолидом.

В целом, исследования биосовместимости ПГА разного состава мало представлены по сравнению с другими классами биополимеров, опубликованные данные не дают однозначного ответа о биосовместимости того или иного типа ПГА. Связано это с тем, что в экспериментах были использованы различ- 
ные типы ПГА различной степени очистки. Анализируемые изделия (пленки, мембраны и др.) были изготовлены различными методами, и далеко не во всех работах биосовместимость матриксов оценена комплексно, т. е. с учетом физико-химических свойств полимеров, структуры и свойств поверхности. Поэтому для ответа на вопрос о том, какие типы ПГА безопасны и наиболее перспективны для применения, необходимы комплексные исследования.

В Институте биофизики Сибирского отделения РАН удалось синтезировать и провести комплексные исследования биосовместимости следующих сополимерных ПГА: двухкомпонентных сополимеров ПЗГБ/4ГБ с включениями 4-гидроксибутирата до $75 \%$, ПЗГБ/ЗГГ с включениями 3-гидроксигексаноата до 70 \% и трехкомпонентных сополимеров 3-гидроксибутирата с 3-гидроксивалератом и 4-гидроксибутиратом (ПЗГБ/ЗГВ/4ГБ), с 3-гидроксивалератом и 3-гидрокисгексаноатом (ПЗГБ/ЗГВ/ЗГГ) (Volova et al., 2014; Шишацкая с соавт., 2013).

Данные типы ПГА представляют большой интерес, так как включение дополнительной фракции помимо 3-гидроксибути- рата приводит к снижению кристалличности полимера меньше 50 \%, при этом материалы обладают высокими показателями механической прочности и удлинения на разрыв, например, для сополимера ПЗГБ/4ГБ с увеличением включения 4ГБ удлинение на разрыв увеличивалось до $700 \%$ против 2,5 \% для ПЗГБ (Шишацкая и др., 2012). На поверхности пленок, полученных из двух- и трехкомпонентных сополимеров, содержащих 4-гидроксибутират, отмечается наличие микропористости с размером пор до 4 мкм, снижение гидрофобности поверхности. Это оказывает значительное влияние на прикрепление и дальнейшее выживание клеток на матриксах.

В ряде работ, выполненных на базе Института биофизики (Николаева и др., 2011; Шишацкая и др., 2013; Volova et al., 2014), показано, что все двух- и трехкомпонентные полимеры в виде пленок по результатам МТТ-теста поддерживали адгезию и пролиферацию клеток на высоком уровне, сопоставимом с ПЗГБ, но на трехкомпонентных сополимерах ПЗГБ/3ГВ/4ГБ количество клеток было выше, чем на гомополимере на $25 \%$, а на ПЗГБ/3ГВ/3ГГ - на $45 \%$ (рис. 1).

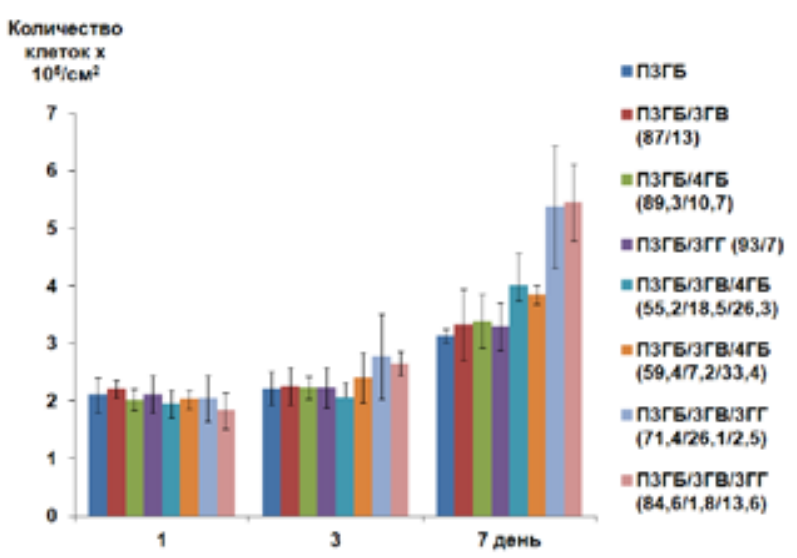

Рис. 1. Количество фибробластов линии NIH 3Т3 на поверхности матриксов, полученных из ПГА разного состава, по результатам МТТ-теста (Николаева и др., 2011; Volova et al., 2014) 

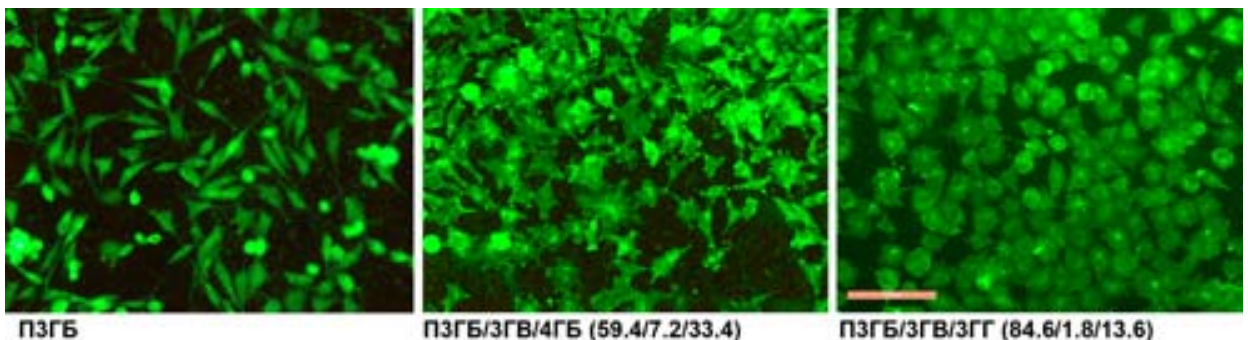

Рис. 2. Морфология фибробластов линии NIH 3Т3 на поверхности матриксов, полученных из ПГА разного состава, на 7-е сут культивирования. Окрашивание FITC. Маркер - 100 мкм (Volova et al., 2014)

Окрашиваниеприкрепленных клеток фаллоидином, конъюгированнымс флуоресцеином (FITC), и электронная микроскопия показали, что клетки на всех матриксах из ПГА были хорошо распластаны, со множеством псевдоподий, что свидетельствует о хорошей прикрепляемости клеток к поверхности и пролиферации (рис. 2).

\section{Заключение}

Таким образом, показано, что все исследованные типы ПГА хорошо поддерживают адгезию и пролиферацию клеток, при этом лучшими биологическими свойствами обладают трехкомпонентные сополимеры. В целом, ПГА - перспективный материал для различных задач клеточной и тканевой инженерии.

\section{Список литературы}

1. Визгунова Э. (2008) О проблемах пересадки органов. Нижегородская правда. 53. http:// www.pravda-nn.ru/archive/number: 357/article: 5292/

2. Волова Т.Г., Севастьянов В.И., Шишацкая Е.И. (2006) Полиоксиалканоаты (ПОА) - биоразрушаемые полимеры для медицины. Красноярск: Платина, 288 с.

3. Готье С.В., Мойсюк Я.Г., Ибрагимова О.С. (2009) Тенденции развития органного донорства и трансплантации в Российской Федерации в 2006-2008 гг. Сообщение (по данным регистра Российского трансплантологического общества). Вестник трансплантологии и искусственных органов. XI (3): 8-16.

4. Краснопольская И. (2011) Сердце в законе. Российская газета. 5556. http://www. rg.ru/2011/08/17/transplantacia.html

5. Николаева Е. Д., Шишацкая Е.И., Мочалов К.Е., Волова Т.Г., Сински Э.Д. (2011) Сравнительное исследование клеточных носителей, полученых из резорбируемых полигидрокисалканоатов различного химического состава. Клеточная трансплантология и тканевая инженерия. VI(4): 54-63.

6. Шишацкая Е.И, Жила Н.О., Николаева Е.Д., Сырвачева Д.А., Сински Э.Дж. (2013) Синтез и исследование сополимеров 3-гидроксибутирата/4-гидроксибуктирата. Перспективные материалы. 3: 20-26.

7. Baier R.E. (1972) The role of surface energy in thrombogenesis. Bull. N.Y. Acad. Med. 48 (2): 257-272.

8. Brodbeck W.G., Colton E., Anderson J.M. (2003) Effects of adsorbed heat labile serum proteins and fibrinogen on adhesion and apoptosis of monocytes/macrophages on biomaterials. J Mater. Sci. Mater. Med. 14: 671-675. 
9. Chee J.-W., Amirul A.A., Tengku Muhammad T.S., Majid M.I.A., Mansor S.M. (2008) The influence of copolymer ratio and drug loading on the biocompatibility of $\mathrm{P}(3 \mathrm{HB}-\mathrm{co}-4 \mathrm{HB})$ synthesized by Cupriavidus sp. (USMAA2-4). Biochem. Eng. J. 38: 314-318.

10. Cheng S.-T., Chen Z.-F., Chen G.-Q. (2008) The expression of cross-linked elastin by rabbit blood vessel smooth muscle cells cultured in polyhydroxyalkanoate scaffolds. Biomaterials. 29: 4187-4194.

11. Doi Y., Kitamura S., Abe H (1995) Microbial synthesis and characterization of poly(3hydroxybutyrate-co-3-hydroxyhaxanoate). Macromolecules. 28: 4822-4828.

12. Drury J.L., Mooney D.J. (2003) Hydrogels for tissue engineering: scaffold design variables and applications. Biomaterials. 24: 4337-4351.

13. Grøndahl L., Chandler-Temple A., Trau M. (2005) Polymeric Grafting of Acrylic Acid onto Poly(3-hydroxybutyrate-co-3-hydroxyvalerate): Surface Functionalization for Tissue Engineering Applications. Biomacromolecules. 6: 2197-2203.

14. Hazer B., Steinbüchel A. (2007) Increased diversification of polyhydroxyalkanoates by modification reactions for industrial and medical applications. Appl. Microbial. Biotechnol. 74: 1-12.

15. Hu S.-G., Jou C.-H., Yang M.C. (2003) Protein adsorption, fibroblast activity and antibacterial properties of poly(3-hydroxybutiric acid-co-3-hydroxyvaleric acid) grafted with chitosan and chitooligosaccharide after immobilized with hyaluronic acid. Biomaterials. 24 (16): 2685-2693.

16. Jansen E.J.P., Sladek R.E.J., Bahar H., Yaffe A., Gijbels M.J., Kuijer R., Bulstra S., Guldemond N.A., Binderman I., Koole L.H. (2005) Hydrophobicity as a design criterion for polymer scaffolds in bone tissue engineering. Biomaterials. 26:4423-4431.

17. Ji Y., Li X.-T., Chen G.-Q. (2008) Interactions between a poly(3-hydroxybutyrate-co-3hydroxyvalerate-co-3-hydroxyhexanoate) terpolyester and human keratinocytes. Biomaterials. 29: 3807-3814.

18. Ji G.-Z., Wei X., Chen G.-Q. (2009) Growth of human umbilical cord Wharton's jelly-derived mesenchymal stem cells on the terpolyester poly(3-hydroxybutyrate-co-3-hydroxyvalerate-co-3hydroxyhexanoate). J. Biomater. Sci. Polym. Ed. 20 (3): 325-339.

19. Kim Y.-J., Bae H.-I., Kwon O. K., Choi M.-S. (2009) Three-dimensional gastric cancer cell culture using nanofiber scaffold for chemosensitivity test. Int. J. Biol. Macromol. 45: 65-71.

20. Köse G.T., Ber S. Kokusuz F., Hasirci V. (2003a) Poly(3-hydroxybutyric-co-3-hydroxyvaleric acid) based tissue engineering matrices. J. Mater. Sci. Mater. Med. 14: 121-126.

21. Köse G.T., Kenar H., Hasirci N., Hasirsci V. (2003b) Macroporous poly(3-hydroxybutyrate-co-3hydroxyvalerate) matrices for bone tissue engineering. Biomaterials. 24: 1949-1958.

22. Köse G.T., Kokusuz F., Özkul A., Soysal Y., Özdemir T., Yildiz C., Hasirci V. (2005) Tissue engineered cartilage on collagen and PHBV matrices. Biomaterials. 26: 5187-5197.

23. Lin H.-R., Ling M.-H., Lin Y.-J. (2009) High strength and low friction of a PAA-alginate-silica hydrogel as potential material for artificial soft tissues. J. Biomat. Sci. 20: 637-652.

24. Liu Q., Chen G.-Q. (2008) In vitro biocompatibility and degradation of terpolyester 3HB-co4HB-co-3HHx, consisting of 3-hydroxybutyrate, 4-hydroxybutyrate and 3-hydroxyhexanoate. J. Biomater. Sci. Polymer Ed. 19 (11) 1521-1533.

25. Lucchesi C., Ferreira B.M.P., Duek E.A.R., Santos A.R., Joazeiro P.P. (2008) Increased response of Vero cells to PHB matrices treated by plasma. J Mater. Sci. Mater. Med. 19: 635-643. 
26. Martin D.P., Williams S. (2003) Medical applications of poly-4-hydroxybutyrate: a strong flexible absorbable biomaterials. Biochem. Eng. J. 16:97-105.

27. Park J., Lakes R.S. (2007) Biomaterials. Springer Science+Bisness Media, 561 p.

28. Pompe T., Keller K., Mothes G., Nitschke M., Teese M., Zimmermann R., Werner C. (2007) Sirface modification of poly(hydroxybutyrate) films to control cell-matrix adgesion. Boimaterials. 28: 28-37.

29. Reusch S., Sparrow A.W., Gardiner J. (1992) Transport of poly- $\beta$-hydroxybutyrate in human plasma. Biochim. Biophys. Acta. 1123: 33-40.

30. Sabokbar A., Pandey R., Athanasou N.A. (2003) The effect of particle size and electrical charge on macrophage-osteoclast differentiation and bone resorption. J. Mater. Sci. Mater. Med. 14: 731738.

31. Saito T., Doi Y. (1994) Microbial synthesis and properties of poly(3-hydroxybutyrate-co-4hydroxybutyrate) in Commamonas acidovorans. Int. J. Biol. Macromol. 16 (2): 99-104.

32. Shin H., Jo S., Mikos A.G. (2003) Biomimetic materials for tissue engineering. Biomaterials. 24: 4353-4364.

33. Shishatskaya E.I., Volova T.G. (2004a) A comparative investigation of biodegradable polyhydroxyalkanoate films as matrices for in vitro cell cultures. J. Mater. Sci. Mater. Med. 15: 915-923.

34. Shishatskaya E.I., Volova T.G., Puzyr A.P., Mogilnaya O.A. (2004b) Tissue response to the implantation of biodegradable polyhydroxyalkanoate suture. J. Mater. Sci. Mater. Med. 15: 719728.

35. Shishatskaya E.I., Chlusov I.A., Volova T.G. (2006) A hybrid PHA-hydroxyapatite composite for biomedical application: production and investigation. J. Biomater. Sci. Polymer Ed. 17 (5): 481498.

36. Shishatskaya E.I. (2008) Biomedical investigation, application of PHA. Macromol. Symposia. 269: 65-81.

37. Sombatmankhong K., Sanchavanakit N., Pavasant P., Supaphol P. (2007) Bone scaffolds from electrospun fiber mats of poly(3-hydroxybutyrate), poly(3-hydroxybutyrate-co-3-hydroxyvalerate) and their blend. Polymer. 48: 1419-1427.

38. Steibuchel A., Valentin H.E. (1995) Diversity of bacterial polyhydroxyalkanoic acids. FEMS Microbial. Lett. 128: 219-228.

39. Tezcaner A., Bugra K., Hasirci V. (2003) Retinal pigment epithelium cell culture on surface modified poly(hydroxybutyrate-co-hydroxyalerate) thin films. Biomaterials. 24: 4573-4583.

40. Van den Dolder J., de Ruijter A.J.E., Spauwen P.H.M., Jansen J.A. (2003) Observation on the effects of BMP-2 on rat bone marrow cells cultured on titanium substrates of different roughness. Biomaterials. 25: 1853-1860.

41. Volova T.G., Kiselev E.G., Vinogradova O.N., Nikolaeva E.D., Chystyakov A., Sukovatiy A.G., Shishatskaya E.I. (2014) A glucose-utilizing strain, Cupriavidus eutrophus в-10646: growth kinetics, characterization and synthesis of multicomponent PHAs. Plos One. 9 (2): $1-15$.

42. Volova T.G., Shishatskaya E.I., Sevastianov V.I., Perova N. (2003) Results of biomedical investigations of PHB and PHB/PHV fibers. Biochem. Eng. J. 16: 125-133. 
43. Wang Y.-W., Wu Q., Chen G.-Q. (2004) Attachment, proliferation and differentiation of osteoblasts on random biopoliester poly(3-hydroxybutyrate-co-3-hydroxyhexanoate) scaffolds. Biomaterials. 25: 669-675.

44. Wang Y.-W., Yang F., Wu Q., Cheng Y.-C., Yu P.H.F., Chen J., Chen G.-Q. (2005) Effect of composition of poly(3-hydroxybutyrate-co-3-hydroxyhexanoate) on growth of fibroblast and osteoblast. Biomaterials. 26: 755-761.

45. Wang Y.Y., Lü L.-X., Shi J.-C., Wang H.-F., Xiao Z.-D., Huang N.-P. (2011) Introduction RGD Peptides on PHBV Films through PEG-Containing Cross-Linkers to Improve the Biocompatibility. Biomacromolecules. 12: 551-559.

46. Williams D.F., Martin D.P., Horowitz D.M., Peoples O.P. (1999) PHA applications: addressing the price performance issue. I. Tissue engineering. Int. J. Biol. Macromol. 25: 111-121.

47. Williams S.F., Martin D.P. (2004) Applications of PHAs in Medicine and Pharmacy. In book "Biopolymers". Wiley-VCH, 4: 91-103.

48. Yang X., Zhao K., Chen G.-Q. (2002) Effect of surface treatment on the biocompatibility of microbial polyhydroxyalkanoates. Biomaterials. 23: 1391-1397.

49. Zinn M., Witholt B., Egli T. (2001) Occurrence, synthesis and medical applications of bacterial polyhydroxyalkanoate. Adv. Drug Deliv. Rev. 53: 5-21. 